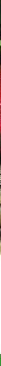

\title{
Recommended future research for biological pest control in greenhouse vegetable crops
}

Augmentative biological control has been applied successfully in greenhouse crops for decades. However, still many problems with pest control exist because the natural enemy species used are insufficiently effective or considered as too expensive and for some pests, natural enemies are simple not available. Moreover, new pests continue to emerge through the invasion of exotic species as a consequence of global trade and warming. Particularly, organic greenhouse crops are vulnerable to such invasions through the lack of chemical correction tools. More research is needed to further develop biological pest control and increase resilience of greenhouse cropping systems. Some suggestions for future research are summarized below.

\section{Problems and reasons for research}

Several pest species such as thrips, whiteflies, aphids, spider mites, caterpillars and leaf miners are very common and cause serious damage to vegetable crops. Biological control is well developed for some pests, but need to be further developed for most pests. In fact, some invasive pest species such as Tuta absoluta, Bemisia tabaci and tomato russet mites have caused increasingly damage to greenhouse vegetables crops. Moreover, some new invasive species can be expected in the future, such as the pepper weevil Anthonomus eugenii. More research is needed to further develop biological pest control and increase resilience of greenhouse cropping systems. We suggest 3 major areas of further research: 1) conservation methods, 3) selection of new species of natural enemies and 3) the integration of arthropod natural enemies with microbials, plant nutrition and greenhouse climate management.

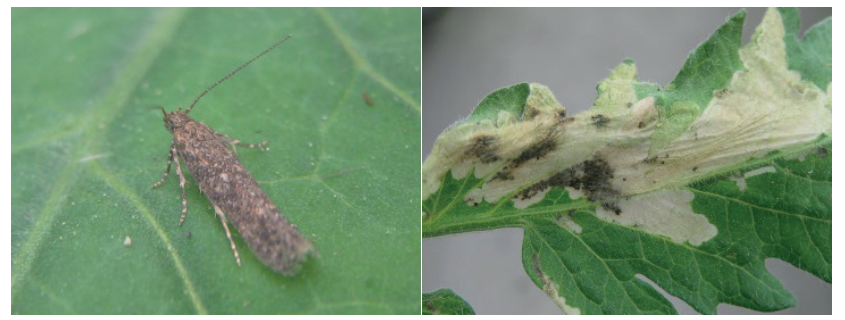

Figure 1. The invastive pest Tuta absoluta.

\section{Conservation of natural enemies}

Methods to conserve natural enemies can be used for both released and naturally occurring populations. The establishment of natural enemies and their population numbers can be enhanced by providing additional resources, such as alternative food, prey, hosts, oviposition sites or shelters.
Supplemental foods sources such as pollen, Ephestia eggs or Artemia cysts are increasingly used to support predatory mites and predatory bugs. Banker plants or flowering plants are often used to support aphid natural enemies such as parasitoids, predatory midges and hoverflies. More research is needed to:

- further develop conservation tools in greenhouse cropping systems in order to create a "standing army" of natural enemies, that is ready to control new pest infestations (for example, new methods need to be developed to support early establishment of lacewings and coccinellid predators);

- better understand food web complexities and interactions among species that are established through conservation methods. Interactions that are potentially negative for biological pest control might be minimized by selecting and releasing natural enemy communities that maximise sustainable pest control.

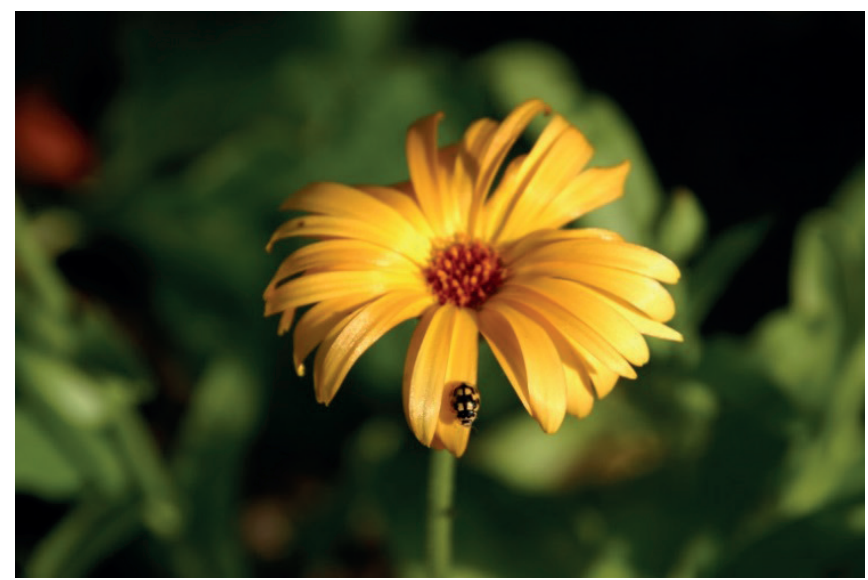

Figure 2. The 14-spotted ladybird beetlet Propylea quatuordecimpuctata feeds upon pollen and nectar from flowers. 


\section{Selection of new species of natural enemies}

By conserving natural enemies and creating a "standing army", the selection of new natural enemies may further shift from more specialist pest adapted natural enemies to more generalist crop adapted natural enemies. An important group of predators for this approach are the true omnivores that feed both on plant and prey, such as "Type IV" predatory mites or mirid predatory bugs. This trait of plant feeding can result in a better establishment of predators on the plants in absence of prey or at low prey densities. However, the zoophytophagous behaviour of predatory bugs may in some cases result in serious plant damage. More research is needed to:

- "unravel" the mechanisms behind the feeding behaviour of omnivorous predators in order to manage their behaviour and optimize pest control while minimizing plant damage;

- select new omnivores that are better adapted to the crops and climatic conditions of that crop;

- select more suitable strains of natural enemies, either collected from different areas or obtained through selective breeding.

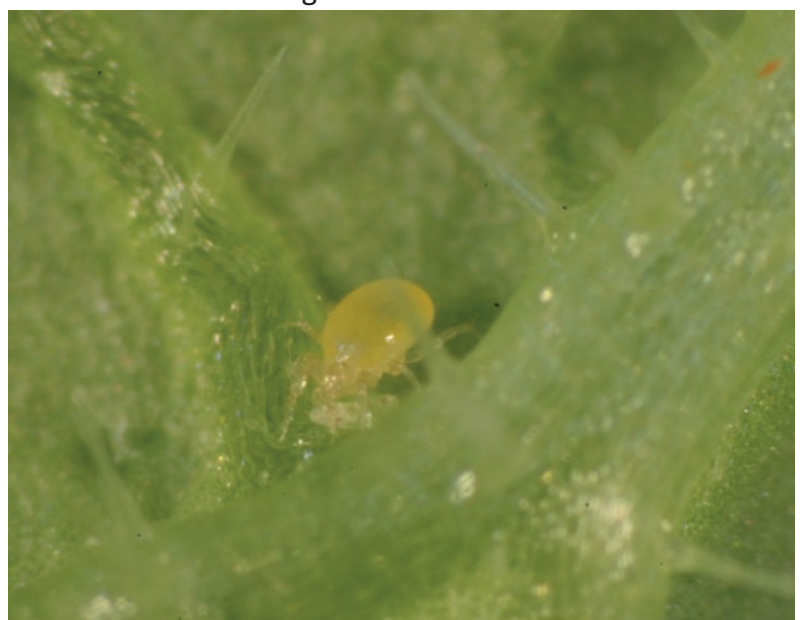

Figure 3. The omnivorous plant-feeding predatory mite Euseius ovalis, feeding on a whitefly larva.

\section{Integration with other measures}

A third development is the increased integration with other factors that interact with the performance of natural enemies. One is the use of microorganisms or botanicals. Obviously, direct negative effects on the survival of arthropod natural enemies should be avoided, but positive interactions may also occur when the natural enemies enhance the dispersal of entomopathogens. Also new application methods of entomopathogens as endophytes may indirectly affect the performance of natural enemies. The same counts for other biotic or abiotic inducers of plant resistance or plant nutrition. New greenhouse climate management techniques that are used to optimize energy saving may also have various effects on the performance of natural enemies and there are still many aspects we do not understand.
Future work on biological pest control inevitable requires a systems approach that recognizes the complexity of biological control programmes on its own and the interactions with other measures for disease control, plant nutrition or energy saving.

\section{Strategic research lines}

More details for future research can be found in the topic specific fact sheets of this series. Summarizing, recommended topics to further explore are listed below:

- Supplemental food for generalist predators

- Banker plants for Entomophthorales of aphids

- Banker and companion (flowering) plants for parasitoids and predators

- Conservation methods for lacewings in and around greenhouses

- Conservation of predaceous Coccinellidae species

- The use of omnivorous predators in pest control

- Training natural enemies to enhance their biocontrol efficacy

- Side-effects of (bio)pesticides and the integration in to organic growing systems

- Adapting the greenhouse climate and light for enhanced biocontrol

- Induced plant responses and natural enemies

- Biological control of invasive pest species

- Management of whitefly transmitted viruses

References: Messelink, G. J., J. Bennison, O. Alomar, B. L. Ingegno, L. Tavella, L. Shipp, E. Palevsky, and F. L. Wäckers. 2014. Approaches to conserving natural enemy populations in greenhouse crops: current methods and future prospects. BioControl 59:377-393.

Gonzalez, F., C. Tkaczuk, M.M. Dinu, Ż. Fiedler, S. Vidal, E. ZchoriFein, and G. J. Messelink. 2016. New opportunities for the integration of microorganisms in to biological pest control systems in greenhouse crops. Journal of Pest Science. In press.

Acknowledgement: This work was supported by COST Action FA1105 "Towards a sustainable and productive EU organic greenhouse horticulture".

DOI: http://dx.doi.org/10.18174/373608

Authors: Gerben Messelink ${ }^{1}$, Barbara Letizia Ingegno ${ }^{2}$ Affiliation: ${ }^{1}$ Wageningen UR Greenhouse Horticulture, The Netherlands, ${ }^{2}$ DISAFA, University of Torino, Italy Contact: gerben.messelink@wur.n

Authors of the pictures: A. van der Linden, C. Bloemhard and G. Messelink

February 2016 